\title{
Role of Clinical Characteristics and Biomarkers at Admission to Predict One-Year Mortality in Elderly Patients with Pneumonia
}

\author{
Astrid Malézieux-Picard ${ }^{1, *}$, Leire Azurmendi ${ }^{2}$, Sabrina Pagano 2,3 ${ }^{(0)}$, Nicolas Vuilleumier ${ }^{2,3,4}$, \\ Jean-Charles Sanchez ${ }^{2,4}$, Dina Zekry ${ }^{1,4}$, Jean-Luc Reny ${ }^{4,5}$, Jérôme Stirnemann ${ }^{5} \mathbb{D}$, Nicolas Garin ${ }^{4,6,+}$, \\ Virginie Prendki ${ }^{1,4,7, \dagger}$ and on behalf of the PneumOldCT Study Group ${ }^{\ddagger}$
}

check for updates

Citation: Malézieux-Picard, A.; Azurmendi, L.; Pagano, S.;

Vuilleumier, N.; Sanchez, J.-C.; Zekry,

D.; Reny, J.-L.; Stirnemann, J.; Garin,

N.; Prendki, V.; et al. Role of Clinical Characteristics and Biomarkers at Admission to Predict One-Year Mortality in Elderly Patients with Pneumonia. J. Clin. Med. 2022, 11 105. https://doi.org/10.3390/ jcm11010105

Academic Editor: Jan Jelrik Oosterheert

Received: 26 November 2021 Accepted: 20 December 2021 Published: 25 December 2021

Publisher's Note: MDPI stays neutral with regard to jurisdictional claims in published maps and institutional affiliations.

Copyright: (c) 2021 by the authors Licensee MDPI, Basel, Switzerland. This article is an open access article distributed under the terms and conditions of the Creative Commons Attribution (CC BY) license (https:// creativecommons.org/licenses/by/ $4.0 /)$
1 Department of Rehabilitation and Geriatrics, Division of Internal Medicine for the Aged, University Hospitals of Geneva, Hôpital des Trois-Chêne, 1226 Thonex, Switzerland; dina.zekry@hcuge.ch (D.Z.); virginie.prendki@hcuge.ch (V.P.)

2 Department of Internal Medecine, Medical Faculty, Geneva University Hospitals, 1205 Geneva, Switzerland; leire.azurmendi@unige.ch (L.A.); sabrina.pagano@hcuge.ch (S.P.); Nicolas.vuilleumier@hcuge.ch (N.V.); jean-charles.sanchez@unige.ch (J.-C.S.)

3 Diagnostic Department, Division of Laboratory Medicine, Geneva University Hospitals, 1205 Geneva, Switzerland

4 Medical Faculty, University of Geneva, 1211 Geneva, Switzerland; jean-luc.reny@hcuge.ch (J.-L.R.); Nicolas.garin@hcuge.ch (N.G.)

5 Department of Internal Medicine, Division of General Internal Medicine, Geneva University Hospitals, 1205 Geneva, Switzerland; jerome.stirnemann@hcuge.ch

6 Department of General Internal Medicine, Riviera Chablais Hospitals, 1847 Rennaz, Switzerland

7 Department of Internal Medicine, Division of Infectious Diseases, Geneva University Hospitals, 1205 Geneva, Switzerland

* Correspondence: astrid-marie.malezieux@hcuge.ch

+ These authors contributed equally to this work.

$\ddagger \quad$ The PneumOldCT Study Group are listed in the data Supplementary Material S1.

Abstract: Background: A hospitalization for community-acquired pneumonia results in a decrease in long-term survival in elderly patients. We assessed biomarkers at admission to predict one-year mortality in a cohort of elderly patients with pneumonia. Methods: A prospective observational study included patients $>65$ years hospitalized with pneumonia. Assessment of PSI, CURB-65, and biomarkers (C-reactive protein (CRP), procalcitonin (PCT), NT-pro-B-type natriuretic peptide (NT-proBNP), interleukin (IL)-6 and -8, tumor necrosis factor alpha (TNF- $\alpha$ ), serum amyloid A (SAA), neopterin (NP), myeloperoxidase (MPO), anti-apolipoprotein A-1 IgG (anti-apoA-1), and antiphosphorylcholine IgM (anti-PC IgM)) was used to calculate prognostic values for one-year mortality using ROC curve analyses. Post hoc optimal cutoffs with corresponding sensitivity (SE) and specificity (SP) were determined using the Youden index. Results: A total of 133 patients were included (median age 83 years [IQR: 78-89]). Age, dementia, BMI, NT-proBNP (AUROC 0.65 (95\% CI: 0.55-0.77)), and IL-8 (AUROC 0.66 (95\% CI: 0.56-0.75)) were significantly associated with mortality, with NT-proBNP (HR 1.01 (95\% CI 1.00-1.02) and BMI (HR 0.92 (95\% CI 0.85-1.000) being independent of age, gender, comorbidities, and PSI with Cox regression. At the cutoff value of $2200 \mathrm{ng} / \mathrm{L}$, NT-proBNP had $67 \%$ sensitivity and 70\% specificity. PSI and CURB-65 were not associated with mortality. Conclusions: NT-proBNP levels upon admission and BMI displayed the highest prognostic accuracy for one-year mortality and may help clinicians to identify patients with poor long-term prognosis.

Keywords: elderly patients; one-year mortality; biomarkers

\section{Introduction}

With an incidence between 1.2 and 11.6 cases for 1000 person per year, communityacquired pneumonia (CAP) is a serious public health problem with a significant morbidity, mortality, and economic burden in Europe [1]. CAP is often a turning point in the life of elderly patients, leading to loss of autonomy, cognitive decline, decompensation of 
comorbidities, and death. Rates of hospitalization are high, with prolonged hospital stays and a high mortality [2]. A hospitalization for CAP results in a decrease in long-term survival in elderly patients [3], partly attributed to the high burden of inflammatory stress, contributing to a high incidence of cardiovascular events after pneumonia $[4,5]$. Hence, biomarkers of inflammation and of cardiac impairment may help refine the prediction of long-term CAP prognosis in elderly patients [6,7].

Among traditional biomarkers of inflammation, C-reactive protein (CRP) and procalcitonin (PCT) are the most frequently used for prognostication of pneumonia in adults [8]. Serum amyloid A protein (SAA), neopterin (NP), myeloperoxidase (MPO), anti-apolipoprotein A-1 IgG (anti-apoA-1), and anti-phosphorylcholine IgM (anti-PC IgM) have been recently investigated in the same context and/or in cardiovascular diseases [9-13]. An association between high levels of pro and anti-inflammatory cytokines (especially interleukin (IL)-1, -6 , and -11) with short- and long-term mortality of CAP has been described, but information concerning elderly patients is lacking [14-18].

The two most used prognosis scores for predicting pneumonia one-month mortality are the Pneumonia Severity Index (PSI) and Confusion, Urea, Respiratory Rate, Blood Pressure, and Age $>65$ years (CURB-65) criteria $[19,20]$. Both combine one or more biomarkers with demographic data and physiological measures, but they have limitations in elderly patients [21,22]. Hence, we aimed to test whether cardiovascular and inflammation biomarkers measured at hospital admission were associated with one-year mortality in elderly patients.

\section{Materials and Methods}

\subsection{Design, Setting, and Population Study}

This prognostic study used data collected in a prospective observational study [23]. Consecutive patients hospitalized with suspected pneumonia in the geriatric and internal medicine wards of Geneva University Hospitals, an 1800-bed tertiary-care institution serving a population of 500,000 inhabitants, were included between 1 May 2015 and 30 April 2016. Eligible patients were older than 65 years and presented symptoms and signs suggestive of a respiratory infection warranting antibiotic treatment. A confirmed diagnosis of pneumonia required demonstration of an acute lung infiltrate on low-dose CT scan (LDCT) and was adjudicated a posteriori by a panel of eleven senior physicians (experts) with expertise in the diagnosis and management of pneumonia and radiologists experienced in thoracic imaging. Experts analyzed clinical, biological, microbiological, and radiological data and patients' outcomes and rated the probability of pneumonia according to a Likert scale (low, intermediate, or high). The reference diagnosis was considered positive (respectively, "negative") if the panel of experts rated the probability of pneumonia "intermediate" or "high" (respectively, "low") on the Likert scale. Patients who had been treated for pneumonia during the previous 6 months or admitted to the intensive care unit were not included. Patients' management, including the choice and duration of antibiotic therapy, followed local guidelines. The study was approved by Geneva's Institutional Review Board (CER-14-250), and it was registered at clinicaltrials.gov (NCT02467192). Written informed consent was obtained from all patients or next of kin.

\subsection{Data Collection}

Demographic data, comorbidities, anamnestic data, vital signs, physical signs, severity scores (PSI, CURB-65), and the results of routinely obtained blood tests (including CRP, PCT, and NT-pro-brain natriuretic peptide (NT-proBNP)) were recorded at admission $[19,20]$.

\subsection{Biomarkers Measurement}

Plasma CRP concentrations were measured via immunoturbidimetry (Roche/Hitachi Cobas c702 systems) and PCT using a rapid assay with a sensitivity of $0.06 \mu \mathrm{g} / \mathrm{L}$ (Kryptor PCT, Brahms, Hennigsdorf). Blood was sampled for IL-6, IL-8, TNF- $\alpha$, SAA, NP, MPO, 
anti-apoA-1 IgG, and anti-PC IgM levels determination within $48 \mathrm{~h}$ after admission. Measurements were performed after completion of the study (Appendix A).

\subsection{Outcome}

Survival status and date of death up to one year were assessed by searching a posteriori in medical records and the register of deaths by an investigator blinded to the measurements of the investigational biomarkers.

\subsection{Data Analysis}

Sample size was determined based on the power calculation of the original study [23]. We used frequencies, percentages, mean with range, and median with interquartile range for descriptive purposes. Variables were compared between patients dead or alive at one year in univariate analysis using One-way Analysis of Variance (ANOVA) for continuous variables and Fisher's exact test or chi-square test for categorical variables, as appropriate. The discrimination ability of each biomarker for one-year mortality was assessed by computing the area under the receiver operating characteristic curve (AUROC) with 95\% CI. Univariate Cox regression was used to obtain the hazard ratio (HR) of death by individual predictive variables. Variables associated with the outcome on univariate analysis with a $p$ value $<0.10$ were entered in a multivariate Cox proportional hazard model using backward conditional regression. PSI and gender were forced in the model, as they are well-described prognostic factors. No imputation was made for missing values.

Optimal cutoff for biomarkers significantly associated with the outcome in multivariate analysis was determined with the Youden index. We plotted Kaplan-Meyer survival curves at optimal cutoff and computed sensitivity, specificity, and positive and negative predictive values. The study sample was determined by the design of the original study. All $p$ values are based on two-tailed tests and are considered significant for $p<0.05$. Data were analyzed using SPSS version 25 (IBM SPSS Statistics for Windows, Version 25.0. Armonk, NY: IBM Corp. Released 2017).

\section{Results}

\subsection{Clinical Characteristics}

Of 200 patients included in the original study, 133 patients (median age 83 years (IQR: 78-89)) had confirmed pneumonia, of whom 35 (26\%) died within one year. Table 1 displays the main characteristics of the patients according to one-year mortality. Sex ratio was approximately 1 . One hundred and seventeen patients (88\%) lived at home. Main comorbidities were heart failure $(n=30,23 \%)$, chronic pulmonary disease $(n=29,22 \%)$, dementia $(n=27,20 \%)$, and chronic renal failure $(n=24,18 \%)$. Most patients presented with cough $(n=120,90 \%)$, dyspnea $(n=95,71 \%)$, and lung crackles $(n=114,86 \%)$.

Table 1. Baseline characteristics of the 133 patients according to one-year mortality.

\begin{tabular}{|c|c|c|c|c|}
\hline \multirow{2}{*}{ Characteristics } & \multicolumn{3}{|c|}{ No $(\%)$ or Mean (SD) } & \multirow[t]{2}{*}{$p$ Value } \\
\hline & Overall (133) & Dead 35 (26) & Alive 98 (74) & \\
\hline Demographics & & & & \\
\hline Female gender & $60(45.1)$ & $15(42.9)$ & $45(45.9)$ & 0.76 \\
\hline Age (years) & $82.9(7.9)$ & $85.5(7.4)$ & $82.0(7.9)$ & 0.02 \\
\hline Smoker (active or past) & $80(60.2)$ & $19(54.3)$ & $61(62.2)$ & 0.41 \\
\hline $\operatorname{BMI}\left(\mathrm{kg} / \mathrm{m}^{2}\right)$ & $24.4(5.1)$ & $22.7(5.4)$ & $24.5(4.9)$ & 0.03 \\
\hline Place of living & & & & 0.14 \\
\hline Home & $117(88.0)$ & $30(85.7)$ & $87(88.8)$ & \\
\hline Nursing home & $11(8.3)$ & $5(14.3)$ & $6(6.1)$ & \\
\hline Other & $5(3.8)$ & 0 & $5(5.1)$ & \\
\hline Hospitalized during last 6 months & $39(29.3)$ & $12(27.6)$ & $27(34.3)$ & 0.45 \\
\hline
\end{tabular}


Table 1. Cont.

\begin{tabular}{|c|c|c|c|c|}
\hline \multirow{2}{*}{ Characteristics } & \multicolumn{3}{|c|}{ No $(\%)$ or Mean (SD) } & \multirow[t]{2}{*}{$p$ Value } \\
\hline & Overall (133) & Dead 35 (26) & Alive 98 (74) & \\
\hline \multicolumn{5}{|l|}{ Comorbidities } \\
\hline Charlson score & & $3.25(2.4)$ & $3.0(1.7)$ & 0.52 \\
\hline Past myocardial infarction & $22(16.5)$ & $8(22.9)$ & $14(14.3)$ & 0.24 \\
\hline Heart failure & $30(22.6)$ & $8(22.9)$ & $22(22.4)$ & 0.96 \\
\hline Dementia & $27(20.3)$ & $11(31.4)$ & $16(16.3)$ & 0.06 \\
\hline Chronic pulmonary disease & $29(21.8)$ & $8(22.9)$ & $21(21.4)$ & 0.86 \\
\hline Diabetes & $7(5.3)$ & $3(8.6)$ & $4(4.1)$ & 0.31 \\
\hline Chronic renal disease & $24(18.0)$ & $5(14.3)$ & $19(19.4)$ & 0.50 \\
\hline Active cancer & $7(5.3)$ & $3(8.6)$ & $4(4.1)$ & 0.31 \\
\hline \multicolumn{5}{|l|}{ Prognostic scores } \\
\hline CURB-65 & $2.2(0.9)$ & $2.4(1.0)$ & $2.2(0.8)$ & 0.15 \\
\hline PSI & $107(26)$ & $113(28)$ & $105(25)$ & 0.63 \\
\hline \multicolumn{5}{|l|}{ Vital signs } \\
\hline Heart rate & $93(18)$ & $95(19)$ & $92(18)$ & 0.41 \\
\hline Respiratory rate & $25(7)$ & $24(6)$ & $25(7)$ & 0.53 \\
\hline Temperature $\left({ }^{\circ} \mathrm{C}\right)$ & $38.0(1.0)$ & $37.8(1.0)$ & $38.1(1.0)$ & 0.10 \\
\hline Systolic blood pressure (mmHg) & $131(23)$ & $133(26)$ & $130(22)$ & 0.53 \\
\hline
\end{tabular}

Abbreviations: BMI, body mass index; CURB-65, confusion, urea $>7 \mathrm{mmol} / \mathrm{L}$, respiratory rate $\geq 30$ breaths $/ \mathrm{min}$, blood pressure $<90 \mathrm{mmHg}$ systolic or $\leq 60 \mathrm{mmHg}$ diastolic, age $\geq 65$; PSI, Pneumonia Severity Index.

\subsection{Biomarkers Results and Outcome}

Table 2 shows the levels of biomarkers at admission according to the outcome and the areas under the receiver operating characteristic curves (AUROCs) for mortality prediction. Data were complete for CRP. There were 18 missing data for NT-proBNP (14\%), 12 for PCT $(9 \%)$, and $3(2 \%)$ for each other biomarker. Only NT-proBNP and IL-8 showed significant discrimination.

Table 2. Biomarkers levels at admission according to one-year mortality, and area under the receiver operating characteristic curve.

\begin{tabular}{|c|c|c|c|c|c|c|}
\hline & \multicolumn{3}{|c|}{ At Admission } & \multirow{2}{*}{$p$ Value * } & \multirow{2}{*}{ AUROC } & \multirow{2}{*}{$p$-Value ${ }^{* *}$} \\
\hline & Overall (133) & Dead (35) & Alive (98) & & & \\
\hline NT-proBNP (ng/L) & $1826(666-3917)$ & 2998 (1459-5971) & 1697 (595-3083) & $<0.01$ & $0.65(0.54-0.77)$ & 0.02 \\
\hline $\mathrm{CRP}(\mathrm{mg} / \mathrm{L})$ & $107(58-208)$ & $82(43-159)$ & $111(58-223)$ & 0.10 & $0.44(0.33-0.54)$ & 0.27 \\
\hline PCT $(\mu \mathrm{g} / \mathrm{L})$ & $0.36(0.14-1.99)$ & $0.57(0.12-2.49)$ & $0.36(0.14-1.93)$ & 0.85 & $0.52(0.40-0.64)$ & 0.71 \\
\hline IL-6 (pg/L) & $8.7(3.7-19.4)$ & $8.9(3.9-18.3)$ & $8.6(3.5-19.6)$ & 0.98 & $0.49(0.38-0.60)$ & 0.86 \\
\hline IL-8 (pg/L) & $17.3(11.1-26.5)$ & $22.8(14.1-29.8)$ & $15.0(9.5-23.3)$ & 0.04 & $0.66(0.56-0.75)$ & $<0.01$ \\
\hline $\mathrm{MPO}(\mathrm{pg} / \mathrm{mL})$ & $204.2(116.9-408.2)$ & $171.2(119.5-297.1)$ & $206.8(114.5-473.7)$ & 0.10 & $0.44(0.34-0.55)$ & 0.33 \\
\hline TNF- $\alpha(\mathrm{pg} / \mathrm{mL})$ & $3.2(2.5-4.8)$ & $3.2(2.3-4.9)$ & $3.3(2.5-4.7)$ & 0.17 & $0.48(0.36-0.60)$ & 0.70 \\
\hline $\mathrm{SAA}(\mu \mathrm{g} / \mathrm{L})$ & $268(252-288)$ & $276(243-293)$ & $267(254-288)$ & 0.44 & $0.50(0.38-0.62)$ & 0.98 \\
\hline anti-apoA-1 IgG (DO) & $0.30(0.18-0.47)$ & $0.30(0.20-0.50)$ & $0.30(0.20-0.40)$ & 0.89 & $0.51(0.39-0.63)$ & 0.87 \\
\hline anti-PC-IgM (U/mL) & $36.3(20.3-61.5)$ & 38.1 (21.4-62.9) & $36.3(20.0-62.3)$ & 0.53 & $0.52(0.40-0.63)$ & 0.75 \\
\hline NP & $6.6(4.5-13.0)$ & $5.9(4.4-17.2)$ & $7.1(4.5-12.6)$ & 0.86 & $0.48(0.37-0.60)$ & 0.78 \\
\hline
\end{tabular}

Medians with interquartile range; AUROC with 95\% CI; ${ }^{*}$ Death vs. alive, ${ }^{* *}$ Null hypothesis, true area $=0.5$ Abbreviations: CRP, C-reactive protein; PCT, procalcitonin; IL, interleukin; MPO, myeloperoxidase; SAA, serum amyloid A; Anti-apo-A1, anti-apolipoprotein A-1; anti-PC IgM, anti-phosphorylcholine IgM; NP, neopterin; DO, optical density; AUROC, operating curve for mortality prediction.

The univariate and multivariate associations of each biomarker with one-year mortality are shown in Table 3. In univariate analysis, older age, lower BMI, and dementia were associated with a higher risk of death. Among biomarkers, NT-proBNP and IL- 8 were associated with death. In a multivariate model adjusting for age, BMI, dementia, IL-8, and NT-proBNP, only NT-proBNP (HR = 1.01 per $100 \mathrm{ng} / \mathrm{mL}(\mathrm{CI} 95 \% 1.00-1.02), p=0.05)$ and BMI (HR 0.92 (CI 95\% 0.85-1.00), $p=0.05$ ) were associated with one-year mortality. 
Table 3. Univariate and multivariate association of biomarkers and clinical characteristics with one-year mortality at admission.

\begin{tabular}{|c|c|c|c|c|}
\hline & \multicolumn{2}{|c|}{ Univariate Analysis } & \multicolumn{2}{|c|}{ Multivariate Analysis } \\
\hline & HR (CI 95\%) & $p$-Value & HR (CI 95\%) & $p$-Value \\
\hline Age (/year) & $1.05(1.01-1.10)$ & 0.02 & & \\
\hline Gender (female) & $0.94(0.48-1.84)$ & 0.87 & & \\
\hline PSI score & $1.01(1.00-1.02)$ & 0.09 & & \\
\hline $\operatorname{BMI}\left(/ \mathrm{kg} / \mathrm{m}^{2}\right)$ & $0.92(0.85-0.99)$ & 0.02 & $0.92(0.85-1.00)$ & 0.05 \\
\hline Dementia & $2.14(1.05-4.38)$ & 0.04 & & \\
\hline NT-proBNP (/100 ngl/L) & $1.01(1.00-1.02)$ & 0.04 & $1.01(1.00-1.02)$ & 0.05 \\
\hline $\operatorname{IL}-8(/ \mathrm{pg} / \mathrm{L})$ & $1.01(1.00-1.01)$ & 0.01 & & \\
\hline
\end{tabular}

Abbreviations: BMI, body mass index; IL, interleukin.

The optimal cutoff was $2200 \mathrm{ng} / \mathrm{L}$ for NT-proBNP at admission, with a sensitivity of $67 \%$ and a specificity of $70 \%$ for one-year mortality (for a normal range of $<300 \mathrm{ng} / \mathrm{L}$ ). Figure 1 displays survival curves for NT-proBNP.

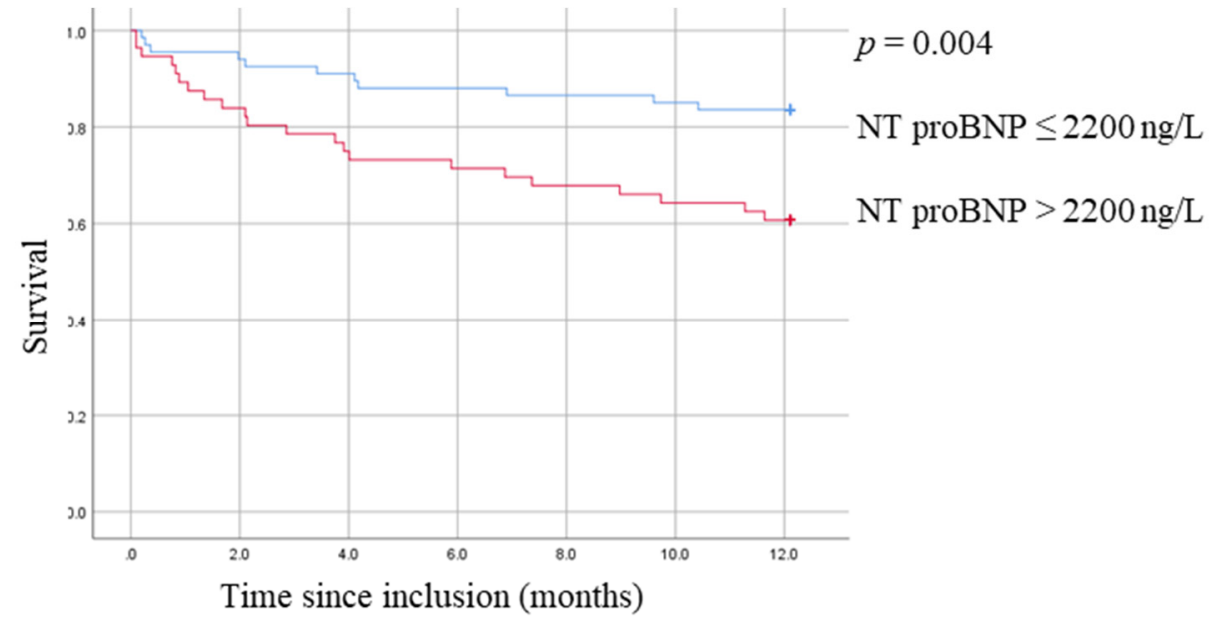

Figure 1. Survival curve of NT pro-BNP value at admission.

Neither CURB-65 (AUROC $=0.57($ CI 95\% 0.45-0.69), $p=0.23$ ) nor PSI score (AUROC $=0.59(\mathrm{CI} 95 \% 0.48-0.70), p=0.12$ ) were associated with one-year mortality.

In a post hoc analysis, we tested whether the association of BMI and NT-proBNP with mortality remained significant after adjusting for the markers of renal function creatinine and urea. When urea was added in the model, aHR of BMI and NT-proBNP did not change; the same was observed after adding creatinine instead of urea (results not shown).

\section{Discussion}

In this cohort of elderly patients hospitalized for pneumonia, only BMI and NTproBNP were independently associated with one-year mortality. Neither usual pneumonia severity scores (PSI and CURB-65) nor any biomarker of inflammation were predictive of one-year mortality.

One-year mortality was $26 \%$, which is coherent with the known poor prognosis of elderly patients after pneumonia $[7,16,24]$. Bruns et al. showed that long-term mortality in patients recovering from CAP was more than 3 times higher than in the general population, and the most frequent causes of death were related to co-morbidities, including malignancy $(27 \%)$, chronic obstructive pulmonary disease $(19 \%)$, and cardiovascular disease (16\%) [25].

Higher NT-proBNP is a powerful predictor of death in a range of conditions. NTproBNP is released from cardiac myocytes in response to mechanical load and wall stress. NT-proBNP is not solely a marker of impaired left ventricular systolic function but also of 
abnormalities of diastolic dysfunction, right ventricular dysfunction, valvular dysfunction, increased pulmonary pressures, and atrial arrhythmias. It has been identified not only as a prognostic biomarker in pulmonary arterial hypertension, myocardial infarction, valvular heart disease, atrial fibrillation, and pulmonary embolism but also as an identifier of sepsis patients at high risk for functional decline [26-28]. Hence it is not surprising that NT-proBNP was an independent predictor of mortality in this cohort of elderly patients hospitalized for pneumonia. Heart failure and other cardiovascular diseases are frequent conditions in patients hospitalized for CAP, and CAP itself can accelerate the pathological process through destabilization of the vascular endothelium and acceleration of the progression of atherosclerosis [5,29]. Eurich et al. showed that CAP increased the risk of heart failure, and some authors have stated that pneumonia itself should be considered an independent cardiovascular risk factor leading to acute myocardial infarction, cardiogenic edema, arrhythmia, and stroke [4,30,31]. Menendez et al. reported that cardiac biomarkers, especially NT-proBNP, can identify patients with CAP at high risk for early and long-term cardiovascular events [24]. A score named the UBMo index developed in a cohort of elderly patients (mean age of 85 years) and incorporating NT-proBNP, urea, and monocyte count was very efficient in identifying patients at high risk of one-year mortality after a pneumonia [7]. An elevated NT-proBNP at admission in an elderly patient hospitalized for pneumonia should prompt consideration of active management of known or latent heart disease, including strengthened follow-up after discharge.

Pneumonia severity scores-namely, PSI and CURB-65-have been developed to predict the risk of mortality at 30 days, in order to guide therapeutic management [19]. Both scores are predictive of the mortality risk up to 6 years after admission in younger patients [32]. However, they may be less accurate in elderly patients. Putot et al. showed that PSI but not CURB-65 correlated with one-year mortality, and their new index named UBMo performed better than PSI score in predicting one-year mortality [7]. In our cohort, no score correlated with mortality. CURB-65 is known to be inaccurate in older patients, as it does not take into account comorbidities and may underestimate the risk of death [33].

We showed that lower BMI was associated with an increased risk of death. Malnutrition is multifactorial, closely related with frailty and comorbidities, and is already known to be associated with a poor long-term outcome in patients with CAP, particularly the elderly [34,35]. As it is amenable to nutritional interventions, malnutrition should be thoroughly evaluated in elderly patients hospitalized for CAP.

Measuring inflammation is theoretically an attractive target for long-term prognostication. Chalmers et al. showed that high levels of CRP at admission and at 3-4 days are related to an increased risk of complications and short-term mortality in CAP [36]. However in a recent publication, increased CRP levels failed to predict the occurrence of cardiovascular events in the short or long term in CAP patients [24]. In our cohort of elderly patients, we did not find that CRP level at admission was associated with one-year mortality. In a similar population, Karasahin et al. described that monitoring changes in serial CRP measurements could be useful for prognosis in elderly patients with infection [37]. They showed that a CRP decrease less than $11 \%$ over $48 \mathrm{~h}$ and less than $20 \%$ over $96 \mathrm{~h}$ was a risk factor for mortality. The literature frequently assessed the association of initial inflammation and in-hospital mortality, as for example, the association of higher PCT and mortality in pneumonia [8]. However, initial values may be insufficient for long-term prognostication, and assessment of the evolution of inflammation should be more relevant.

As for newer biomarkers, SAA is correlated with CRP in CAP [38]. Measurement of SAA in patients with ventilation-acquired pneumonia had a good predictive value for mortality [9]. NP is a marker of cellular immunity associated with the severity of infection and mortality in critically ill patients [10,39]. In chronic obstructive pulmonary disease (COPD), high NP levels during an exacerbation episode correlated with short-term prognosis [8]. Anti-apo-A1 is a mediator of inflammation and atherosclerosis, correlated with inflammation, endothelial dysfunction, and rupture of atheromatous plaques [40]. Anti-PC IgM is part of the innate immune system and is known as a major factor in the 
defense against pneumococcus [41,42]. Anti-PC IgM also prevents the development of atheromatous plaque, inhibiting the exit of OxLDL and the PAF [43]. MPO is an enzyme released by activated neutrophils during an infection [13]. In the ICU setting, MPO levels were related to 30-day mortality, and high MPO levels increased mortality risk on top of the APACHE IV score [12]. Unfortunately, we could not show any link between these newer biomarkers and long-term survival in our cohort.

Pinargote-Celorio et al. recently confirmed previous findings suggesting that proinflammatory cytokines (IL-6, IL-8) and anti-inflammatory cytokines (IL-10) could predict one-month mortality for CAP in elderly patients [14,18]. IL-6 is a cytokine of the acute phase and has been mostly described as a risk factor for early mortality [15,44]. IL-8 is an inflammatory chemokine that plays a key role in the recruitment and activation of neutrophils during inflammation, in atherogenesis, atherosclerotic plaque destabilization, neovascularization, and angiogenesis $[45,46]$. It has been shown that higher concentrations of IL-8 at admission were associated with in hospital mortality in ICU patients with severe CAP or sepsis $[47,48]$. Of note, few studies have been performed in elderly patients. In our study, IL-6 and IL-8 on admission were not associated with long-term mortality.

Our study is an original study and has several strengths. It included consecutive elderly patients with multiple comorbidities who had extensive diagnostic testing. A robust reference standard was used, based on CT scan findings. According to recent findings, a gold standard based on chest X-ray may lead to frequent misclassifications [23]. Moreover, we tested many inflammatory and cardiac biomarkers at admission.

Conversely, our study has some limitations. It is a single-center study with a small sample size. Some patients received previous antibiotics that may have altered biomarker levels and performance. Another limitation is that biomarkers are not static, and their measurement at a specific time does not give a complete picture of the condition. Finally, prior host status, severity of the disease, or other factors can also influence biomarkers.

\section{Conclusions}

In conclusion, a lower BMI and a higher NT-proBNP level at admission were independently associated with one-year mortality after a hospitalization for pneumonia in elderly patients. Destabilization of cardiovascular known or latent disease may be an important cause of mortality in this population, and a more accurate prognostication may be achieved through cardiac biomarker measurement, potentially allowing personalization of subsequent management. A thorough nutritional assessment should be performed, and nutritional interventions should be considered when relevant. These results need to be evaluated in larger and multicenter trials.

Supplementary Materials: The following supporting information can be downloaded at: https: / /www.mdpi.com/article/10.3390/jcm11010105/s1, S1. PneumOldCT Study Group.

Author Contributions: Conceptualization, V.P. and N.G.; methodology, V.P., J.S., J.-C.S., N.V. and N.G.; software, L.A. and N.G.; validation, J.-C.S., N.V., N.G., V.P., J.S. and J.-L.R.; formal analysis, V.P., A.M.-P., L.A., S.P. and N.G.; investigation, V.P., A.M.-P., J.-C.S., N.V. and L.A.; resources, L.A., J.-C.S. and N.V.; data curation, V.P.; writing-original draft preparation, A.M.-P., L.A., S.P., D.Z., N.V., J.-C.S., N.G., J.S., J.-L.R. and V.P.; writing-review and editing, A.M.-P., V.P. and N.G.; visualization, V.P., N.G., J.-L.R. and D.Z.; supervision, V.P. and N.G.; project administration, V.P.; funding acquisition, V.P. All authors have read and agreed to the published version of the manuscript.

Funding: The study was supported by grants from the Geneva University Hospitals (HUG) (Research \& Development Grant, Medical Directorate, HUG) and the Ligue Pulmonaire Genevoise, a non-profit association involved in caring for patients with respiratory diseases.

Institutional Review Board Statement: The study was conducted according to the guidelines of the Declaration of Helsinki, and the study was approved by the Institutional Review Board of Geneva (CER 14-250). The study was also registered in www.clinicaltrials.gov (NCT02467192, first submitted on 27 May 2015). 
Informed Consent Statement: Informed consent was obtained from all subjects involved in the study or from their representative.

Data Availability Statement: The data presented in this study are available on request from the corresponding author.

Acknowledgments: We thank the patients and their families for their participation in this study. We also thank all members of the PneumOldCT study group, clinicians, radiology technicians, research nurses, and case managers who helped us enroll our participants, as well as the Clinical Research Center of Hôpitaux Universitaires de Geneve (HUG).

Conflicts of Interest: The authors declare no conflict of interest. The funders had no role in the design of the study; in the collection, analyses, or interpretation of data; in the writing of the manuscript; or in the decision to publish the results.

\section{Appendix A}

Determination of NP was performed using a competitive enzyme-linked immunosorbent assay (ELISA) (ELItest ${ }^{\circledR}$ Neopterin-Screening, Brahms). Anti-apoA-1 IgG was measured using frozen plasma according to a previously validated protocol [49]. Anti-PC IgM levels were assessed using a commercially available enzyme-linked immunosorbent assay kit (CVDefine ${ }^{\mathrm{TM}}$; Athera Biotechnologies, Uppsala, Sweden). Plasma concentration of MPO was assessed using the commercial Quantikine ELISA kit from R\&D Systems (Minneapolis, MN, USA). Plasma levels of IL-6, IL-8, TNF- $\alpha$, and SAA were measured using the MesoScale Discovery (MSD) platform (Rockville, MD, USA) on the SQ120 instrument [50].

\section{References}

1. Welte, T.; Torres, A.; Nathwani, D. Clinical and Economic Burden of Community-Acquired Pneumonia among Adults in Europe. Thorax 2012, 67, 71-79. [CrossRef] [PubMed]

2. Martin, G.S.; Mannino, D.M.; Moss, M. The Effect of Age on the Development and Outcome of Adult Sepsis. Crit. Care Med. 2006, 34, 15-21. [CrossRef] [PubMed]

3. Bordon, J.; Wiemken, T.; Peyrani, P.; Paz, M.L.; Gnoni, M.; Cabral, P.; del Carmen Venero, M.; Ramirez, J.; CAPO Study Group. Decrease in Long-Term Survival for Hospitalized Patients with Community-Acquired Pneumonia. Chest 2010, 138, $279-283$. [CrossRef]

4. Corrales-Medina, V.F.; Alvarez, K.N.; Weissfeld, L.A.; Angus, D.C.; Chirinos, J.A.; Chang, C.-C.H.; Newman, A.; Loehr, L.; Folsom, A.R.; Elkind, M.S.; et al. Association between Hospitalization for Pneumonia and Subsequent Risk of Cardiovascular Disease. JAMA 2015, 313, 264-274. [CrossRef]

5. Corrales-Medina, V.F.; Suh, K.N.; Rose, G.; Chirinos, J.A.; Doucette, S.; Cameron, D.W.; Fergusson, D.A. Cardiac Complications in Patients with Community-Acquired Pneumonia: A Systematic Review and Meta-Analysis of Observational Studies. PLoS Med. 2011, 8, e1001048. [CrossRef]

6. Krüger, S.; Ewig, S.; Giersdorf, S.; Hartmann, O.; Suttorp, N.; Welte, T.; German Competence Network for the Study of Community Acquired Pneumonia (CAPNETZ) Study Group. Cardiovascular and Inflammatory Biomarkers to Predict Short- and Long-Term Survival in Community-Acquired Pneumonia: Results from the German Competence Network, CAPNETZ. Am. J. Respir. Crit. Care Med. 2010, 182, 1426-1434. [CrossRef]

7. Putot, A.; Tetu, J.; Perrin, S.; Bailly, H.; Piroth, L.; Besancenot, J.-F.; Bonnotte, B.; Chavanet, P.; Charles, P.-E.; Sordet-Guépet, H.; et al. A New Prognosis Score to Predict Mortality After Acute Pneumonia in Very Elderly Patients. J. Am. Med. Dir. Assoc. 2016, 17, 1123-1128. [CrossRef] [PubMed]

8. Lacoma, A.; Rodríguez, N.; Prat, C.; Ruiz-Manzano, J.; Andreo, F.; Ramírez, A.; Bas, A.; Pérez, M.; Ausina, V.; Domínguez, J. Usefulness of Consecutive Biomarkers Measurement in the Management of Community-Acquired Pneumonia. Eur. J. Clin. Microbiol. Infect. Dis. 2012, 31, 825-833. [CrossRef]

9. Abo-Hagar, H.H.; Abo-Elezz, A.A.E.; Mehrez, M.; Mabrouk, M.M.; Elshora, O.A. Diagnostic Efficacy of Serum Amyloid A Protein and Soluble Intercellular Adhesion Molecule 1 in Pediatric Ventilator-Associated Pneumonia. J. Intensive Care Med. 2019, 34, 503-510. [CrossRef] [PubMed]

10. Baydar, T.; Yuksel, O.; Sahin, T.T.; Dikmen, K.; Girgin, G.; Sipahi, H.; Kurukahvecioglu, O.; Bostanci, H.; Sare, M. Neopterin as a Prognostic Biomarker in Intensive Care Unit Patients. J. Crit. Care 2009, 24, 318-321. [CrossRef] [PubMed]

11. Pizzini, A.; Lunger, F.; Sahanic, A.; Nemati, N.; Fuchs, D.; Weiss, G.; Kurz, K.; Bellmann-Weiler, R. Diagnostic and Prognostic Value of Inflammatory Parameters Including Neopterin in the Setting of Pneumonia, COPD, and Acute Exacerbations. COPD 2017, 14, 298-303. [CrossRef] 
12. Schrijver, I.T.; Kemperman, H.; Roest, M.; Kesecioglu, J.; de Lange, D.W. Myeloperoxidase Can Differentiate between Sepsis and Non-Infectious SIRS and Predicts Mortality in Intensive Care Patients with SIRS. Intensive Care Med. Exp. 2017, 5, 43. [CrossRef] [PubMed]

13. Davies, M.J. Myeloperoxidase-Derived Oxidation: Mechanisms of Biological Damage and Its Prevention. J. Clin. Biochem. Nutr. 2011, 48, 8-19. [CrossRef] [PubMed]

14. Pinargote-Celorio, H.; Miralles, G.; Cano, M.; Caparros, E.; Portilla, J.; González-Alcaide, G.; Ramos Rincón, J.M. Cytokine Levels Predict 30-Day Mortality in Octogenarians and Nonagenarians with Community-Acquired Pneumonia: A Retrospective Observational Study. Eur. J. Clin. Microbiol. Infect. Dis. 2020, 39, 299-307. [CrossRef]

15. Bacci, M.R.; Leme, R.C.P.; Zing, N.P.C.; Murad, N.; Adami, F.; Hinnig, P.F.; Feder, D.; Chagas, A.C.P.; Fonseca, F.L.A. IL-6 and TNF- $\alpha$ Serum Levels Are Associated with Early Death in Community-Acquired Pneumonia Patients. Braz. J. Med. Biol Res. 2015, 48, 427-432. [CrossRef] [PubMed]

16. Guertler, C.; Wirz, B.; Christ-Crain, M.; Zimmerli, W.; Mueller, B.; Schuetz, P. Inflammatory Responses Predict Long-Term Mortality Risk in Community-Acquired Pneumonia. Eur. Respir. J. 2011, 37, 1439-1446. [CrossRef] [PubMed]

17. Yende, S.; D'Angelo, G.; Kellum, J.A.; Weissfeld, L.; Fine, J.; Welch, R.D.; Kong, L.; Carter, M.; Angus, D.C.; GenIMS Investigators. Inflammatory Markers at Hospital Discharge Predict Subsequent Mortality after Pneumonia and Sepsis. Am. J. Respir. Crit. Care Med. 2008, 177, 1242-1247. [CrossRef] [PubMed]

18. Kellum, J.A.; Kong, L.; Fink, M.P.; Weissfeld, L.A.; Yealy, D.M.; Pinsky, M.R.; Fine, J.; Krichevsky, A.; Delude, R.L.; Angus, D.C.; et al. Understanding the Inflammatory Cytokine Response in Pneumonia and Sepsis: Results of the Genetic and Inflammatory Markers of Sepsis (GenIMS) Study. Arch. Intern. Med. 2007, 167, 1655-1663. [CrossRef] [PubMed]

19. Fine, M.J.; Auble, T.E.; Yealy, D.M.; Hanusa, B.H.; Weissfeld, L.A.; Singer, D.E.; Coley, C.M.; Marrie, T.J.; Kapoor, W.N. A Prediction Rule to Identify Low-Risk Patients with Community-Acquired Pneumonia. N. Engl. J. Med. 1997, 336, 243-250. [CrossRef]

20. Lim, W.; van der Eerden, M.M.; Laing, R.; Boersma, W.; Karalus, N.; Town, G.; Lewis, S.; Macfarlane, J. Defining Community Acquired Pneumonia Severity on Presentation to Hospital: An International Derivation and Validation Study. Thorax 2003, 58, 377-382. [CrossRef] [PubMed]

21. Restrepo, M.I.; Faverio, P.; Anzueto, A. Long-Term Prognosis in Community-Acquired Pneumonia. Curr. Opin. Infect. Dis. 2013, 26, 151-158. [CrossRef] [PubMed]

22. Chen, J.-H.; Chang, S.-S.; Liu, J.J.; Chan, R.-C.; Wu, J.-Y.; Wang, W.-C.; Lee, S.-H.; Lee, C.-C. Comparison of Clinical Characteristics and Performance of Pneumonia Severity Score and CURB-65 among Younger Adults, Elderly and Very Old Subjects. Thorax 2010, 65, 971-977. [CrossRef]

23. Prendki, V.; Scheffler, M.; Huttner, B.; Garin, N.; Herrmann, F.; Janssens, J.-P.; Marti, C.; Carballo, S.; Roux, X.; Serratrice, C.; et al. Low-Dose Computed Tomography for the Diagnosis of Pneumonia in Elderly Patients: A Prospective, Interventional Cohort Study. Eur. Respir. J. 2018, 51. [CrossRef] [PubMed]

24. Menéndez, R.; Méndez, R.; Aldás, I.; Reyes, S.; Gonzalez-Jimenez, P.; España, P.P.; Almirall, J.; Alonso, R.; Suescun, M.; MartinezDolz, L.; et al. Community-Acquired Pneumonia Patients at Risk for Early and Long-Term Cardiovascular Events Are Identified by Cardiac Biomarkers. Chest 2019, 156, 1080-1091. [CrossRef]

25. Bruns, A.H.W.; Oosterheert, J.J.; Cucciolillo, M.C.; El Moussaoui, R.; Groenwold, R.H.H.; Prins, J.M.; Hoepelman, A.I.M. CauseSpecific Long-Term Mortality Rates in Patients Recovered from Community-Acquired Pneumonia as Compared with the General Dutch Population. Clin. Microbiol. Infect. 2011, 17, 763-768. [CrossRef] [PubMed]

26. Mueller, C.; McDonald, K.; de Boer, R.A.; Maisel, A.; Cleland, J.G.F.; Kozhuharov, N.; Coats, A.J.S.; Metra, M.; Mebazaa, A.; Ruschitzka, F.; et al. Heart Failure Association of the European Society of Cardiology Practical Guidance on the Use of Natriuretic Peptide Concentrations. Eur. J. Heart Fail. 2019, 21, 715-731. [CrossRef]

27. Lewis, R.A.; Durrington, C.; Condliffe, R.; Kiely, D.G. BNP/NT-ProBNP in Pulmonary Arterial Hypertension: Time for Point-ofCare Testing? Eur. Respir. Rev. 2020, 29. [CrossRef] [PubMed]

28. Custodero, C.; Wu, Q.; Ghita, G.L.; Anton, S.D.; Brakenridge, S.C.; Brumback, B.A.; Efron, P.A.; Gardner, A.K.; Leeuwenburgh, C.; Moldawer, L.L.; et al. Prognostic Value of NT-ProBNP Levels in the Acute Phase of Sepsis on Lower Long-Term Physical Function and Muscle Strength in Sepsis Survivors. Crit. Care 2019, 23, 230. [CrossRef]

29. Corrales-Medina, V.F.; Madjid, M.; Musher, D.M. Role of Acute Infection in Triggering Acute Coronary Syndromes. Lancet Infect. Dis. 2010, 10, 83-92. [CrossRef]

30. Eurich, D.T.; Marrie, T.J.; Minhas-Sandhu, J.K.; Majumdar, S.R. Risk of Heart Failure after Community Acquired Pneumonia: Prospective Controlled Study with 10 Years of Follow-Up. BMJ 2017, 356, j413. [CrossRef] [PubMed]

31. Dela Cruz, C.S.; Wunderink, R.G.; Christiani, D.C.; Cormier, S.A.; Crothers, K.; Doerschuk, C.M.; Evans, S.E.; Goldstein, D.R.; Khatri, P.; Kobzik, L.; et al. Future Research Directions in Pneumonia. NHLBI Working Group Report. Am. J. Respir. Crit. Care Med. 2018, 198, 256-263. [CrossRef]

32. Alan, M.; Grolimund, E.; Kutz, A.; Christ-Crain, M.; Thomann, R.; Falconnier, C.; Hoess, C.; Henzen, C.; Zimmerli, W.; Mueller B.; et al. Clinical Risk Scores and Blood Biomarkers as Predictors of Long-Term Outcome in Patients with Community-Acquired Pneumonia: A 6-Year Prospective Follow-up Study. J. Intern. Med. 2015, 278, 174-184. [CrossRef]

33. Ma, H.M.; Ip, M.; Woo, J. Effect of Age and Residential Status on the Predictive Performance of CURB-65 Score. Intern. Med. J. 2015, 45, 300-304. [CrossRef] [PubMed] 
34. Yeo, H.J.; Byun, K.S.; Han, J.; Kim, J.H.; Lee, S.E.; Yoon, S.H.; Jeon, D.; Kim, Y.S.; Cho, W.H. Prognostic Significance of Malnutrition for Long-Term Mortality in Community-Acquired Pneumonia: A Propensity Score Matched Analysis. Korean J. Intern. Med. 2019, 34, 841-849. [CrossRef] [PubMed]

35. Yoon, H.-Y.; Shim, S.S.; Kim, S.J.; Lee, J.H.; Chang, J.H.; Lee, S.H.; Ryu, Y.J. Long-Term Mortality and Prognostic Factors in Aspiration Pneumonia. J. Am. Med. Dir. Assoc. 2019, 20, 1098-1104. [CrossRef] [PubMed]

36. Chalmers, J.D.; Singanayagam, A.; Hill, A.T. C-Reactive Protein Is an Independent Predictor of Severity in Community-Acquired Pneumonia. Am. J. Med. 2008, 121, 219-225. [CrossRef] [PubMed]

37. Karasahin, O.; Tasar, P.T.; Timur, O.; Yıldırım, F.; Binici, D.N.; Sahin, S. The Value of C-Reactive Protein in Infection Diagnosis and Prognosis in Elderly Patients. Aging Clin. Exp. Res. 2018, 30, 555-562. [CrossRef]

38. Takata, S.; Wada, H.; Tamura, M.; Koide, T.; Higaki, M.; Mikura, S.-I.; Yasutake, T.; Hirao, S.; Nakamura, M.; Honda, K.; et al. Kinetics of C-Reactive Protein (CRP) and Serum Amyloid A Protein (SAA) in Patients with Community-Acquired Pneumonia (CAP), as Presented with Biologic Half-Life Times. Biomarkers 2011, 16, 530-535. [CrossRef] [PubMed]

39. Ruokonen, E.; Ilkka, L.; Niskanen, M.; Takala, J. Procalcitonin and Neopterin as Indicators of Infection in Critically Ill Patients. Acta Anaesthesiol. Scand. 2002, 46, 398-404. [CrossRef] [PubMed]

40. Vuilleumier, N.; Montecucco, F.; Hartley, O. Autoantibodies to Apolipoprotein A-1 as a Biomarker of Cardiovascular Autoimmunity. World J. Cardiol. 2014, 6, 314-326. [CrossRef]

41. Mold, C.; Rodic-Polic, B.; Du Clos, T.W. Protection from Streptococcus Pneumoniae Infection by C-Reactive Protein and Natural Antibody Requires Complement but Not Fc Gamma Receptors. J. Immunol. 2002, 168, 6375-6381. [CrossRef] [PubMed]

42. McDaniel, L.S.; Benjamin, W.H.; Forman, C.; Briles, D.E. Blood Clearance by Anti-Phosphocholine Antibodies as a Mechanism of Protection in Experimental Pneumococcal Bacteremia. J. Immunol. 1984, 133, 3308-3312. [PubMed]

43. Rubini Gimenez, M.; Pagano, S.; Virzi, J.; Montecucco, F.; Twerenbold, R.; Reichlin, T.; Wildi, K.; Grueter, D.; Jaeger, C.; Haaf, P.; et al. Diagnostic and Prognostic Value of Autoantibodies Anti-Apolipoprotein A-1 and Anti-Phosphorylcholine in Acute Non-ST Elevation Myocardial Infarction. Eur. J. Clin. Investig. 2015, 45, 369-379. [CrossRef] [PubMed]

44. Siljan, W.W.; Holter, J.C.; Nymo, S.H.; Husebye, E.; Ueland, T.; Aukrust, P.; Mollnes, T.E.; Heggelund, L. Cytokine Responses, Microbial Aetiology and Short-Term Outcome in Community-Acquired Pneumonia. Eur. J. Clin. Investig. 2018, 48, e12865. [CrossRef] [PubMed]

45. Baggiolini, M.; Walz, A.; Kunkel, S.L. Neutrophil-Activating Peptide-1/Interleukin 8, a Novel Cytokine That Activates Neutrophils. J. Clin. Investig. 1989, 84, 1045-1049. [CrossRef]

46. Ramji, D.P.; Davies, T.S. Cytokines in Atherosclerosis: Key Players in All Stages of Disease and Promising Therapeutic Targets. Cytokine Growth Factor Rev. 2015, 26, 673-685. [CrossRef] [PubMed]

47. Lee, Y.-L.; Chen, W.; Chen, L.-Y.; Chen, C.-H.; Lin, Y.-C.; Liang, S.-J.; Shih, C.-M. Systemic and Bronchoalveolar Cytokines as Predictors of In-Hospital Mortality in Severe Community-Acquired Pneumonia. J. Crit. Care 2010, 25, 176.e7-176.e13. [CrossRef] [PubMed]

48. Anderson, B.J.; Calfee, C.S.; Liu, K.D.; Reilly, J.P.; Kangelaris, K.N.; Shashaty, M.G.S.; Lazaar, A.L.; Bayliffe, A.I.; Gallop, R.J.; Miano, T.A.; et al. Plasma STNFR1 and IL8 for Prognostic Enrichment in Sepsis Trials: A Prospective Cohort Study. Crit. Care 2019, 23, 400. [CrossRef]

49. Vuilleumier, N.; Bas, S.; Pagano, S.; Montecucco, F.; Guerne, P.-A.; Finckh, A.; Lovis, C.; Mach, F.; Hochstrasser, D.; Roux-Lombard, P.; et al. Anti-Apolipoprotein A-1 IgG Predicts Major Cardiovascular Events in Patients with Rheumatoid Arthritis. Arthritis Rheum. 2010, 62, 2640-2650. [CrossRef]

50. Azurmendi, L.; Degos, V.; Tiberti, N.; Kapandji, N.; Sanchez, P.; Sarrafzadeh, A.; Puybasset, L.; Turck, N.; Sanchez, J.-C. Measuring Serum Amyloid A for Infection Prediction in Aneurysmal Subarachnoid Hemorrhage. J. Proteome Res. 2015, 14, 3948-3956. [CrossRef] [PubMed] 